\title{
Pancreas divisum: a cause of idiopathic acute pancreatitis
}

\author{
Wendy K. Ng, Osman Tarabain MD
}

A previously healthy 23-year-old woman presented to hospital with 2 months of intermittent dyspepsia following meals and acute-onset epigastric pain, nausea and vomiting. Based on the results of laboratory investigations (lipase > 1900 [normal < 286] U/L), acute pancreatitis was diagnosed. It was treated conservatively with analgesics and intravenous hydration. The results of other laboratory tests, including those for amylase, leukocytes and creatinine, were within normal limits. No obvious reversible causes of pancreatitis were initially identified. The patient reported consuming alcohol rarely. Ultrasonography of the abdomen ruled out gallstones. A computed tomography (CT) scan of her abdomen and pelvis showed that her pancreas had a relatively normal appearance; however, assessment was limited because of minimal intra-abdominal fat in her upper abdomen in the region of the pancreatic head. After 2 days, the patient's pain had improved but her lipase level remained above $500 \mathrm{U} / \mathrm{L}$. The patient's abdominal pain and lipase levels (829 U/L) increased after she resumed eating solid foods.

Ultrasonography performed 21 days after admission



Figure 1: An endoscopic retrograde cholangiopancreatography image of the pancreas of a 23-year-old-woman demonstrating cannulation of the major papilla. The cystic duct is joined with the common hepatic duct to form the common bile duct. However, there is no pancreatic duct joining the common bile duct as occurs in the normal pancreatic anatomy. This is because the pancreatic duct drains into the minor papilla, as is the case with pancreas divisum.

\section{Key points}

- Pancreas divisum is a congenital anomaly that occurs in about $10 \%$ of the population and is a potentially treatable cause of acute pancreatitis.

- The lifetime risk of pancreatitis for patients with pancreas divisum $(5 \%-10 \%)$ is similar to risk in the general population.

- Pancreas divisum should be considered in patients with acute pancreatitis when the usual causes of pancreatitis (e.g., gallstones, alcohol) have been excluded.

- Endoscopic ultrasonography is a safe first-line investigation for patients with recurrent pancreatitis; endoscopic retrograde cholangiopancreatography is the test of choice for diagnosis and management if pancreas divisum is suspected.

showed gallbladder "sludge" with no evidence of stones. Laparoscopic cholecystectomy was performed. The results of tests for autoimmune pancreatitis (antinuclear antibodies and IgG subtypes) were negative. However, the patient had persistent abdominal pain and an elevated lipase level above 1000 U/L. Twenty-eight days after admission, she underwent magnetic resonance cholangiopancreatography, which showed pancreas divisum. Following endoscopic retrograde cholangiopancreatography (Figure 1), a sphincterotomy on the major papilla was performed with no noteworthy clinical improvement. Six weeks later, endoscopic retrograde cholangiopancreatography was repeated, with sphincterotomy of the minor papilla and placement of a stent. The patient's pain resolved, and her lipase levels returned to normal within 14 days.

\section{Discussion}

\section{Anatomy and epidemiology}

In over $90 \%$ of healthy people, the dorsal and ventral endodermal pancreatic buds fuse to form the adult pancreas. However, in about $10 \%$ of the population, fusion does not occur, resulting in pancreas divisum (Figure 2), which is the most common congenital ductal anomaly of the pancreas. ${ }^{1}$ The classic anatomy of pancreas divisum consists of a small ventral duct, which drains through the larger major papilla, and the larger dorsal duct, which drains through the smaller minor papilla.,3

In patients with a large dorsal duct, the majority of the pancreatic secretions (up to $2000 \mathrm{~mL}$ daily) pass through this duct. ${ }^{2}$ Pancreas divisum through the minor papilla (instead of the major papilla) can result in inadequate drainage and pain

From the Schulich School of Medicine and Dentistry $(\mathrm{Ng})$, the University of Western Ontario, London, Ont.; and the Department of General Internal Medicine (Tarabain), Hôtel-Dieu Grace Hospital, Windsor, Ont. 


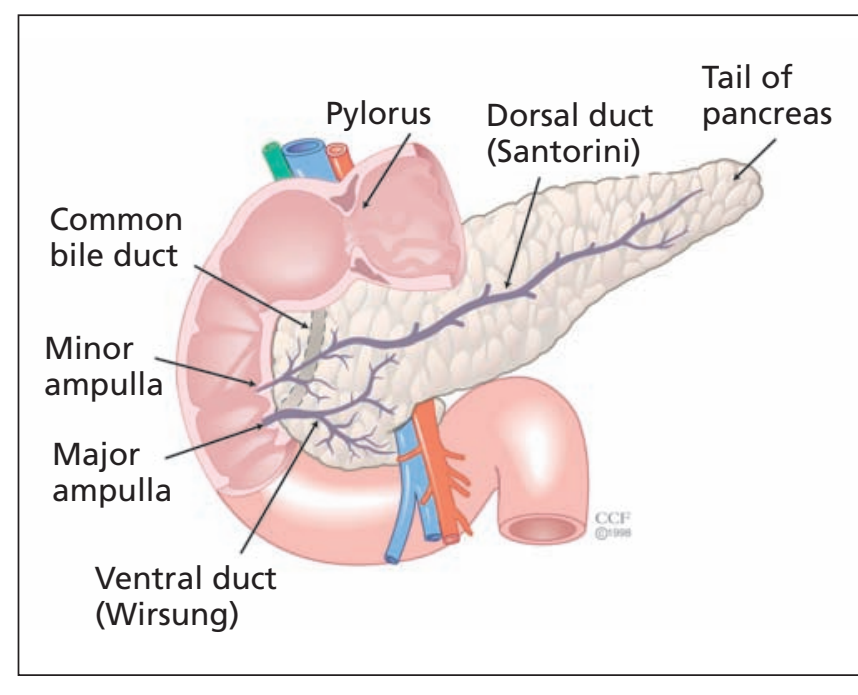

Figure 2: Pancreas divisum. Reproduced with permission of The Cleveland Clinic Centre for Medical Art and Photography, 2009.

caused by obstruction. ${ }^{4}$ Obstructive symptoms and pancreatitis typically affect adults.

Compared with patients with normal pancreatic anatomy who have pancreatitis, patients whose pancreatitis is a result of pancreas divisum are typically younger, less likely to drink alcohol, more likely to be female and more likely to have a pat- tern of recurrent acute pancreatitic attacks. ${ }^{4}$ Pancreas divisum may have a genetic component, including mutations or variants of the cystic fibrosis transmembrane conductance regulator gene (e.g., IVS8-5T variant). ${ }^{5}$ However, the exact relation between genetic markers and pancreas divisum is unknown.

Pancreas divisum is reported in $3 \%-7 \%$ of cases of acute pancreatitis. ${ }^{2,3,6}$ Pancreas divisum underlies $12 \%-50 \%$ of cases of acute pancreatitis in patients whose pancreatitis would otherwise be considered idiopathic. ${ }^{4}$ However, no clear association exists between pancreas divisum and chronic pancreatitis. ${ }^{7}$

Patients with pancreas divisum who are otherwise well (e.g., those whose pancreas divisum is discovered during imaging done for another purpose) can be reassured that they have only a $5 \%-10 \%$ lifetime risk of developing pancreatitis, ${ }^{8}$ which is similar to the risk in the general population. ${ }^{9}$

\section{Investigations}

Although CT scans and transabdominal scans are often used for patients with acute and chronic pancreatitis (e.g., to rule out other causes such as gallstones and pseudocyst formation), pancreas divisum is not reliably detected by such scans. In most cases, pancreas divisum is best diagnosed by endoscopic retrograde cholangiopancreatography, magnetic resonance cholangiopancreatography or endoscopic ultrasonography (Table 1). Endoscopic ultrasonography is a safe first-line test to evaluate the condition of most patients with acute recurrent pancreatitis. ${ }^{10}$ Although magnetic resonance cholan-

Table 1: Comparison of imaging techniques for the diagnosis and management of pancreas divisum

\begin{tabular}{|c|c|c|}
\hline Technique & Role & Limitations \\
\hline $\begin{array}{l}\text { Endoscopic retrograde } \\
\text { cholangiopancreatography }\end{array}$ & $\begin{array}{l}\text { Allows investigation and management } \\
\text { of the condition in the same setting }\end{array}$ & $\begin{array}{l}\text { - Irritation of the pancreas during endoscopy may } \\
\text { cause pancreatitis } \\
\text { - Relative contraindications include coagulopathies } \\
\text { and anticoagulation therapy }\end{array}$ \\
\hline $\begin{array}{l}\text { Abdominal computed } \\
\text { tomography }\end{array}$ & $\begin{array}{l}\text { - Useful for the evaluation of pancreatic } \\
\text { glandular anatomy and other causes of } \\
\text { pancreatitis } \\
\text { - May allow visualization of the ductal } \\
\text { anatomy }\end{array}$ & - Exposure of the patient to radiation \\
\hline $\begin{array}{l}\text { Magnetic resonance } \\
\text { cholangiopancreatography }\end{array}$ & $\begin{array}{l}\text { - Allows noninvasive investigation of the } \\
\text { condition }\end{array}$ & $\begin{array}{l}\text { - Cost and availability of magnetic resonance } \\
\text { imaging scanners } \\
\text { - General limitations, including morbid obesity, } \\
\text { claustrophobia and the presence of metallic } \\
\text { foreign bodies } \\
\text { - Exposure of the patient to radiation } \\
\text { - Endoscopic retrograde cholangiopancreatography } \\
\text { is still required for management }\end{array}$ \\
\hline $\begin{array}{l}\text { Transabdominal } \\
\text { ultrasonography }\end{array}$ & $\begin{array}{l}\text { - Generally not useful in making the diagnosis } \\
\text { May be of some use for evaluating } \\
\text { pancreatic glandular anatomy and other } \\
\text { causes of pancreatitis } \\
\text { - Secretin-stimulated ultrasound* can identify } \\
\text { anomalous ductal paths }\end{array}$ & $\begin{array}{l}\text { - Efficacy is limited by patient's body fat, } \\
\text { positioning and bowel location }\end{array}$ \\
\hline $\begin{array}{l}\text { Endoscopic } \\
\text { ultrasonography }\end{array}$ & $\begin{array}{l}\text { - Allows endoscopic investigation of } \\
\text { pancreatic anatomy by use of an ultrasound } \\
\text { probe }\end{array}$ & $\begin{array}{l}\text { - Irritation of the pancreas during endoscopy may } \\
\text { cause pancreatitis }\end{array}$ \\
\hline
\end{tabular}

*Sequential measurement of pancreatic duct size following intravenous administration of secretin. 


\section{Box 1: Causes of pancreatitis ${ }^{11}$}

- Alcohol abuse

- Gallstones

- Tropical pancreatitis

- Toxic or metabolic pancreatitis

- Traumatic pancreatitis (e.g., caused by endoscopic retrograde cholangiopancreatography or surgery)

- Congenital pancreaticobiliary malformations (pancreas divisum, pancreaticobiliary maljunction, choledochocele, annular pancreas)

- Autoimmune pancreatitis

- Hereditary pancreatitis, such as cationic trypsinogen (serine protease 1 or PRSS1), serine protease inhibitor Kazal type 1 (SPINK1) and cystic fibrosis transmembrane conductance regulator

- Vascular or ischemic pancreatitis

- Post-irradiation pancreatitis

giopancreatography has limited availability and high cost, it is rapidly becoming the noninvasive test of choice to diagnose the condition. However, endoscopic retrograde cholangiopancreatography remains the test of choice to diagnose or manage pancreas divisum for most patients. ${ }^{10}$ The sensitivity and specificity of the different imaging modalities for diagnosing pancreas divisum have yet to be compared.

\section{Management}

The initial approach to the care of a patient with acute pancreatitis includes an awareness of the causes of the condition (Box 1). Management of acute pancreatitis includes hemodynamic stabilization, parenteral analgesia, temporary withholding of oral foods and liquids, abstaining from alcohol, and eventual dietary changes including a low-fat diet and possible supplementation of pancreatic enzymes.

During endoscopic retrograde cholangiopancreatography, treatment options for pancreas divisum include sphincterotomy, papillary dilatation and stent insertion. In 1 study that included 19 patients, the rate of improvement (indicated by reductions in hospital admissions, emergency department visits and episodes of pancreatitis) during a 2-year follow-up period was higher among patients who received a stent than among those who did not $(90 \%$ v. $11 \%){ }^{12}$

Following endoscopic sphincterotomy of the minor papilla in 52 patients with pancreas divisum, improved symptoms were reported more frequently among patients with acute recurrent pancreatitis than among those with chronic pancreatitis $(76.5 \%$ v. $27.3 \%)$ or chronic pancreatic pain $(76.5 \%$ v. $26.1 \%$ ) over a mean follow-up of 1.7 years. ${ }^{13}$

Surgical resection of the pancreas or drainage procedures can be performed for patients with incapacitating pain if conservative measures fail. ${ }^{6}$ Typically, surgeons therapeutically decompress the dorsal gland ${ }^{9}$ because that is where pathologic changes are usually isolated. A stent in the pancreatic duct leading to the minor papilla can be left in place temporarily to avoid possible ductal injury and restenosis. In a series of 15 patients, the overall results following pancreatic resection were good after follow-up of 2-7 years. ${ }^{6}$ However, in patients who do not have the gross changes associated with chronic pancreatitis, pancreatic resection is an overly aggressive treatment. ${ }^{3}$

\section{Summary}

Overall, pancreas divisum is an underrecognized cause of many cases of recurrent acute pancreatitis. Pancreas divisum should be suspected if more common causes, such as alcohol use and gallstones, have been excluded. Although endoscopic ultrasound is a safe first-line investigation for assessing pancreatitis, endoscopic retrograde cholangiopancreatography remains the gold standard for diagnosing pancreas divisum.

Ultimately, magnetic resonance cholangiopancreatography may be used instead of endoscopic retrograde cholangiopancreatography if such imaging is more readily available; however, endoscopic retrograde cholangiopancreatography remains the modality of choice for interventional management. Pancreas divisum is a potentially treatable cause of acute pancreatitis.

This article has been peer reviewed.

Competing interests: None declared.

\section{REFERENCES}

1. Klein SD, Affronti JP. Pancreas divisum, an evidence-based review: Part I, pathophysiology. Gastrointest Endosc 2004;60:419-24.

2. Warshaw AL, Richter JM, Schapiro RH. The cause and treatment of pancreatitis associated with pancreas divisum. Ann Surg 1983;198:443-52.

3. Britt LG, Samuels AD, Johnson JW Jr. Pancreas divisum: Is it a surgical disease? Ann Surg 1983;197:654-62.

4. Cotton PB. Congenital anomaly of pancreas divisum as cause of obstructive pain and pancreatitis. Gut 1980;21:105-14.

5. Dray X, Fajac I, Bienvenu T, et al. Association of Pancreas Divisum and Recurrent Acute Pancreatitis with the IVS8-5T-12TG Allele of the CFTR Gene and CFTR Dysfunction. Pancreas 2007;35:90-3.

6. Blair AJ, Russell CG, Cotton PB. Resection for pancreatitis in patients with pancreas divisum. Ann Surg 1984;200:590-4

7. Spicak J, Poulova P, Plucnarova J, et al. Pancreas divisum does not modify the natural course of chronic pancreatitis. J Gastroenterol 2007;42:135-9.

8. Quest L, Lombard M. Pancreas divisum: opinion divisa. Gut 2000;47:317-9.

9. DiMagno MJ, DiMagno EP. Chronic pancreatitis. Curr Opin Gastroenterol 2005;21:544-54

10. Al-Haddad M, Wallace MB. Diagnostic approach to patients with acute idiopathic and recurrent pancreatitis: What should be done? World J Gastroenterol 2008;14:1007-10.

11. Frossard JL, Steer ML, and Pastor CM. Acute pancreatitis. Lancet 2008;71:143-52.

12. Lans JI, Geenen JE, Johanson JF, et al. Endoscopic therapy in patients with pancreas divisum and acute pancreatitis: a prospective, randomized, controlled clinical trial. Gastrointest Endosc 1992;38:430-4.

13. Lehman GA, Sherman S, Nisi R, et al. Pancreas divisum: results of minor papilla sphincterotomy. Gastrointest Endosc 1993;39:1-8.

The section Cases presents brief case reports that convey clear, practical lessons. Preference is given to common presentations of important rare conditions, and important unusual presentations of common problems. Articles start with a brief summary (100 words) outlining the case and its relevance to a general audience. The case presentation follows (500 words maximum) as well as a discussion of the underlying condition (1000 words maximum). Generally, up to 5 references are permitted, and visual elements (e.g., tables of the differential diagnosis, clinical features or diagnostic approach) are encouraged. Written consent from patients for publication of their story is a necessity and should accompany submissions. See information for authors at www.cmaj.ca. 